cover the $\$ 1.4$ billion, Congress passed the Helium Privatization Act in 1996. The Act called for the U.S. government to sell off any helium in excess of about 17 million scm on a straight line basis between January 1, 2005 and January 1, 2015. The selling began in 2005 after a NRC study reported that doing so would not have a substantial impact on helium users, barring any large unforeseen changes.

However, the non-U.S. demand for helium has increased significantly over the last 15 years, due to new industrial applications in areas like semiconductors and optical-fiber fabrication facilities. New helium-producing facilities have been built outside of the United States, but U.S. Federal Helium Reserve sales still account for half of U.S. helium demand and nearly one-third of global demand.

One of the main concerns that may drive Congressional action is that the price of crude helium has long been tied to a minimum price outlined in the 1996 Act that was set so as to recover the $\$ 1.4$ billion. Since it has not been tied to the market, the selling price of helium has not reflected its limited supply. "It is shameful how we squandered the helium we once held in reserve," said Richardson of the low cost at which much of the helium reserve was sold. Tying the price of helium to the minimum outlined in the 1996 Act enabled the BLM to sell much of the reserve, but caused rapid variations in the price and availability of open-market helium that were difficult for federally funded individual and small-scale researchers to ac- commodate. After the 2010 NRC report, BLM changed its pricing methodology to better reflect the market demand, but many think Congress needs to take further action.

Senators like Jeff Bingaman of New Mexico, chair of the Senate Committee on Energy and Natural Resources, would like to recover the U.S. investment in the reserve, but to do so in a way that ensures federal users like the Departments of Energy and Defense long-term access to crude helium, protects the nonrenewable nature of helium through a new pricing system tied to the market, and stimulates the development of private sources of helium.

Kendra Redmond

\section{Reactor Institute Delft to receive funding} www.rid.tudelft.nl

T he Reactor Institute Delft, home to Delft University of Technology's nuclear research reactor, will receive financial support from the state government to implement a program called the Optimized Yield-for Science, Technology, and Education - of Radiation, or OYSTER. Together with the funds that TU Delft and commercial parties are raising, this financial injection will give the institute the boost it needs to be able to maintain its position as the center of scientific expertise in nuclear and radiation research and education. The extra funds mean that the nuclear reactor can be fitted with a Cold Source. New, innovative research instruments will also be developed. These are essential for the development of materials for sustainable energy technology and for research into the detection and treatment of cancer, among other things.

The Cold Source - a device that can slow down the speed of neutrons-enables the neutrons to be more accurately guided for applications such as materials research. Director of the Reactor Institute Delft and TU Delft dean Tim van der Hagen said, "The slower neutrons are. . . much better at detecting abnormalities in materials, which means, for example, that the efficiency of solar panels and the capacity, charge rate, and safety of batteries can be drastically improved."

The Reactor Institute Delft is the Dutch center for multidisciplinary scientific research and education in reactor physics, neutron and positron radiation, radiation detection, and radiochemistry. A large part of the research focuses on medical applications, such as the production of medical isotopes and the diagnosis and treatment of cancer. In addition, new materials are being developed for sustainable energy such as solar cells and batteries, and work is being carried out to develop the nuclear reactors of the future.

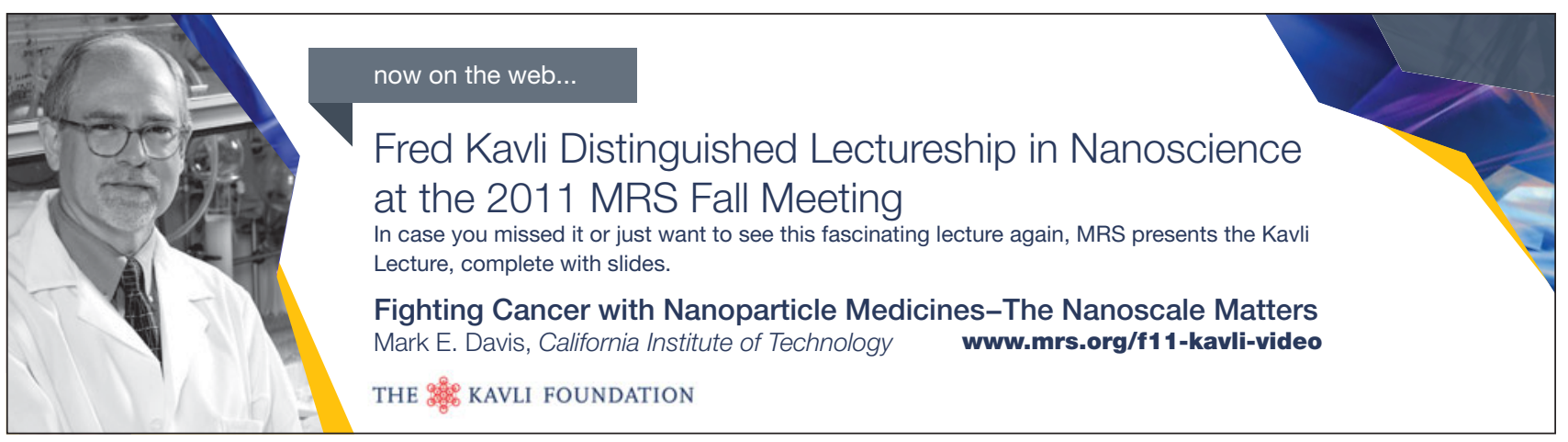

